\title{
Immediate risk of non-cancer deaths after a cancer diagnosis
}

\author{
Pengcheng Yang ${ }^{1 \dagger}$, Yongqiang Zheng ${ }^{2,3{ }^{\dagger}}$, Jiayuan Chen ${ }^{2}$, Haotian $\mathrm{Ma}^{2}$, Kaixu $\mathrm{Yu}^{2}$, Ying Chen ${ }^{2}$, Yun Yang ${ }^{2}$ and \\ Bian $\mathrm{Wu}^{2^{*}}$
}

\begin{abstract}
Background: Receiving a cancer diagnosis may trigger immediate fatal non-cancer health outcomes in addition to dying of cancer itself. We aim to investigate the full pattern of non-cancer deaths in patients within a year of a cancer diagnosis.

Methods: Patients diagnosed with cancer between 1990 and 2016 were identified from the SEER program. Standardized mortality ratios (SMRs) were calculated to characterize the relative risks of non-cancer deaths compared with the general population.
\end{abstract}

Results: Among 7,366,229 patients, 241,575 non-cancer deaths (15.9\%) were recorded in the first year following a cancer diagnosis. The relative risk of non-cancer deaths was 2.34-fold (95\% confidence interval (CI): $2.33-2.35)$ that of the general population. The majority of non-cancer deaths were caused by cardiovascular diseases (21.8\%), followed by infectious diseases (7.2\%). Significant elevations in mortality risks were observed for nearly all noncancer causes, particularly in infectious diseases (SMR: 5.08; 95\% Cl: 5.03-5.13). Patients with liver cancer (SMR: 12.29; 95\% Cl: 12.06-12.53) were at the highest risk of early non-cancer deaths. The risks of non-cancer deaths were highest within the first month after diagnosis, and decreased rapidly thereafter.

Conclusions: Risks of non-cancer deaths vary by the types of causes and anatomic sites of cancer. Our data underscore the importance of close observation and early multidisciplinary care for noncancer conditions in patients who have recently received a cancer diagnosis.

Keywords: Cancer diagnosis, Non-cancer deaths, Comorbidity, SEER program, Standardized mortality ratios (SMRs)

\section{Introduction}

As recent progress in cancer prevention, diagnosis, and treatment has prolonged survival of patients with cancer, risk of non-cancer deaths is now becoming a great threat to the health of cancer survivors [1]. There are several reasons for this. First, as cancer is largely a disease of elder persons, cancer survivorship and treatment occur in the context of comorbidities. Secondly, the disease itself and its treatment have substantial impact on the

\footnotetext{
* Correspondence: bianwu@hust.edu.cn

${ }^{\dagger}$ Pengcheng Yang and Yongqiang Zheng co-first authors.

${ }^{2}$ Cancer Center, Union Hospital, Tongji Medical College, Huazhong University of Science and Technology, Wuhan 430022, China

Full list of author information is available at the end of the article
}

short-term and long-term health of the cancer patients, including organ damage, functional disabilities, as well as secondary malignancies. Thirdly, psychological disabilities such as anxiety, depression, stress, fear of recurrence may also lead to certain adverse health outcomes, such as suicide and cardiovascular disease (CVD) $[2,3]$. Although a number of the studies have focused on survivorship of long-term cancer survivors $[1,3,4]$, the short-term survivorship following a cancer diagnosis has not been well studied. It has been shown that the relative risks in suicides and CVD were significantly elevated in this particular short peroid, probably due to the high levels of distress and psychiatric symptoms resulting

C C The Author(s). 2021 Open Access This article is licensed under a Creative Commons Attribution 4.0 International License, which permits use, sharing, adaptation, distribution and reproduction in any medium or format, as long as you give appropriate credit to the original author(s) and the source, provide a link to the Creative Commons licence, and indicate if changes were made. The images or other third party material in this article are included in the article's Creative Commons licence, unless indicated otherwise in a credit line to the material. If material is not included in the article's Creative Commons licence and your intended use is not permitted by statutory regulation or exceeds the permitted use, you will need to obtain permission directly from the copyright holder. To view a copy of this licence, visit http://creativecommons.org/licenses/by/4.0/ The Creative Commons Public Domain Dedication waiver (http://creativecommons.org/publicdomain/zero/1.0/) applies to the data made available in this article, unless otherwise stated in a credit line to the data. 
from the cancer diagnosis [3, 4]. However, risks of deaths from other non-cancer causes remain unclear.

Understanding the patterns of death is key to predicting the health care needs of a growing cancer population and in developing a public health strategy. This study intended to comprehensively assess all the non-cancer causes of death within the first year immediately after a cancer diagnosis. It also aimed to identify the subgroups at particular risk of early death from non-cancer causes.

\section{Materials and methods}

\section{Data sources and study population}

A retrospective cohort study was performed using data from the Surveillance, Epidemiology, and End Results (SEER) program. As a system of population-based cancer registries from the National Cancer Institute, this program routinely collects and reports data on cancer demographics, incidence, follow-up data, anatomic sites, morphology, stage, therapy, and socioeconomic status of cancer patients in the United States [5].

All patients diagnosed with cancer between 1990 and 2016 were identified from the SEER 18 database (2019 submission) using the SEER*Stat software version 8.3.6 [5]. Data from patients with only one cancer or those on the first primary cancer were included. Patients were excluded if their diagnosis was obtained exclusively from death certificates or autopsy reports. We further excluded patients without complete follow-up information, including the duration of follow-up, age at diagnosis or race (Fig. 1). To compare with the general population, mortality data of the general US population registered by the National Center for Health Statistics between 1990 and 2016, were also obtained from the SEER database [6].

Since it is a publicly available database, access to the SEER data required a signed research data agreement form. Institutional Review Board approval and informed consent were waived for the data obtained from the SEER database, as the study did not directly involve human subjects, and all data were anonymized.

\section{Definition of variables}

All patients were observed from the time of cancer diagnosis until death within 1 year, exiting the follow-up within 1 year, surviving up to 1 year or the end of the study (December 31, 2016). Non-cancer deaths occurring in the first year after a cancer diagnosis were chosen as the events of interest. For patients who survived more than one year, the first-year follow-up after the cancer diagnosis was taken into account. Among patients included in this study, we evaluated the following variables: age at diagnosis, sex, race, year of diagnosis, marital status, survival in months, cause of death, anatomic site, cancer stage, surgical therapy, chemotherapy and radiotherapy.

Non-cancer deaths (deaths from any medical cause other than cancer) were defined based on SEER cause-of-death classification variables obtained from the death certificates, and were categorized into 26 major groups [7]. The recodes were completed

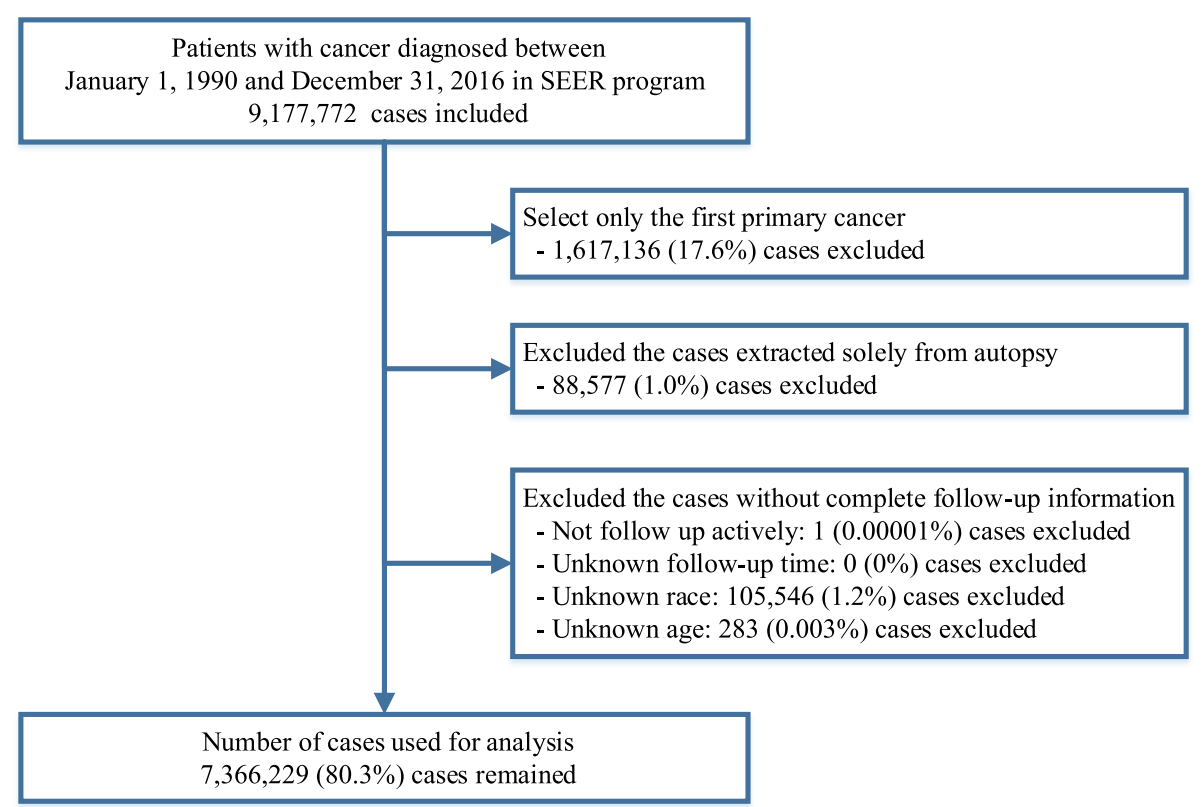

Fig. 1 Flow chart of inclusion and exclusion criteria for cases included in this study 
according to the international classification of diseases codes ninth version (ICD-9) for deaths that occurred between 1990 and 1998, or ICD-10 for the deaths that occurred between 1999 and 2016. These groups were further consolidated into 7 broad categories, namely infectious diseases, CVD, respiratory diseases, gastrointestinal and liver diseases, renal diseases, external injuries, and other causes [7, 8]. Although deaths from benign, or unknown behavior neoplasms were also classified as noncancer deaths by the SEER program, these deaths were not considered as non-cancer deaths during our analyses. The remaining 25 major types of non-cancer cause were included in our analysis.

As the SEER database records the duration of survival in months, and a month was the shortest time interval available for analysis, survival durations shorter than 1 month are recorded as 0 months in the SEER program. Therefore, according to standard epidemiologic conventions, patients with durations of survival coded as zero were converted to half month periods [9].

\section{Statistical analysis}

The mortality rates for non-cancer causes were calculated as the number of non-cancer deaths that occurred within 1 year of diagnosis, divided by person-years of follow-up. For patients who died or exited the study within 1 year from the diagnosis, the actual follow-up duration was used. For patients who survived more than 1 year after diagnosis, the follow-up time was recorded as such. The standardized mortality ratios (SMRs) and corresponding 95\% confidence intervals (CIs) of noncancer deaths were calculated according to previously published methods [9-12]. The SMRs were estimated as the ratios of observed to expected number of noncancer deaths within the year following a cancer diagnosis. The observed values represented the number of deaths from certain causes in cancer patients, whereas the expected values represented the number of individuals who died of the same causes in the general population, with a similar distribution of age, sex, race, and calendar year. For age and calendar year used in the course of standardization, five-year categories were created and the values at the time of diagnosis were adopted. The race group used in the standardization included White, Black, American Indian/Alaska Native and Asian or Pacific Islander. The 95\% CI of the SMRs were obtained using an approximation from the Poisson distribution [9, 13].

All statistical tests were 2 -sided, and $P<.05$ were considered statistically significant. Analyses were performed using the SEER*Stat version 8.3.6 (US Department of Health and Human Services) and the $\mathrm{R}$ version 3.52 (The R Project for Statistical Computing) statistical software package $[5,14]$.

\section{Results}

Baseline characteristics

A total of 7,366,229 patients with cancer were identified for analysis. During follow-up, 1,518,097 deaths were recorded in the first year after diagnosis, of which 241,575 were due to non-cancer causes; this represented $15.9 \%$ of total deaths. Compared with the general population, the relative risk of non-cancer deaths in patients with a cancer diagnosis was 2.34 (95\% CI: 2.33-2.35) within the first year after diagnosis. Most deaths from non-cancer causes occurring within the first year were observed in patients who were 60 years or older $(83.5 \%)$, male $(58.1 \%)$ and white of race $(80.7 \%)$.

Compared with the general population, non-cancer death risks within the first year after diagnosis were higher among those with an age of 20 to 39 years (SMR: 19.88; 95\% CI: 19.43-20.34), of Asian or Pacific Islander ethnicity (SMR: 3.82; 95\% CI: 3.62-4.03), unmarried (SMR: 2.92; 95\% CI: 2.90-2.93), with distant metastases (SMR: 4.13; 95\% CI: 4.10-4.17), not treated with surgery (SMR: 3.57; 95\% CI: 3.55-3.59), and not treated with radiotherapy (SMR: 2.60; 95\% CI: 2.592.61). The baseline characteristics are detailed in Table 1 . The mortality from non-cancer causes was higher within the first year (SMR: 2.34; 95\% CI: $2.33-$ 2.35) than that after a year, among cancer patients (SMR, 1.81; 95\% CI: 1.80-1.81).

\section{Mortality for major types of non-cancer causes}

On cause-specific analysis, the first leading noncancer cause of death was CVD (21.8\%), followed by infectious diseases (7.2\%), and respiratory diseases (4.4\%). Compared with the general population, the SMRs were particularly high for infectious diseases (SMR: 5.08; 95\% CI: 5.03-5.13) and gastrointestinal and liver diseases (SMR: 4.62; 95\% CI: 4.51-4.73). Although lower, the mortality rates for other causes were higher than that of the general population. Patients with cancer have relatively high SMR from CVD (SMR: 2.02; 95\% CI: 2.01-2.04) and suicide (SMR: 2.85; 95\% CI: 2.74-2.96) in the first year after diagnosis (Table 2).

\section{Anatomic sites associated with higher risks of non-cancer deaths}

In the site-specific analysis, data are presented only for persons with those forms of cancer in which 20,000 person-years or more of survival time was accrued in the data obtained from the SEER registries. Of the different cancer sites, lung cancer was responsible for the highest number of non-cancer deaths (17.7\%), followed by colorectal $(12.3 \%)$ and prostate cancer $(7.3 \%)$. 


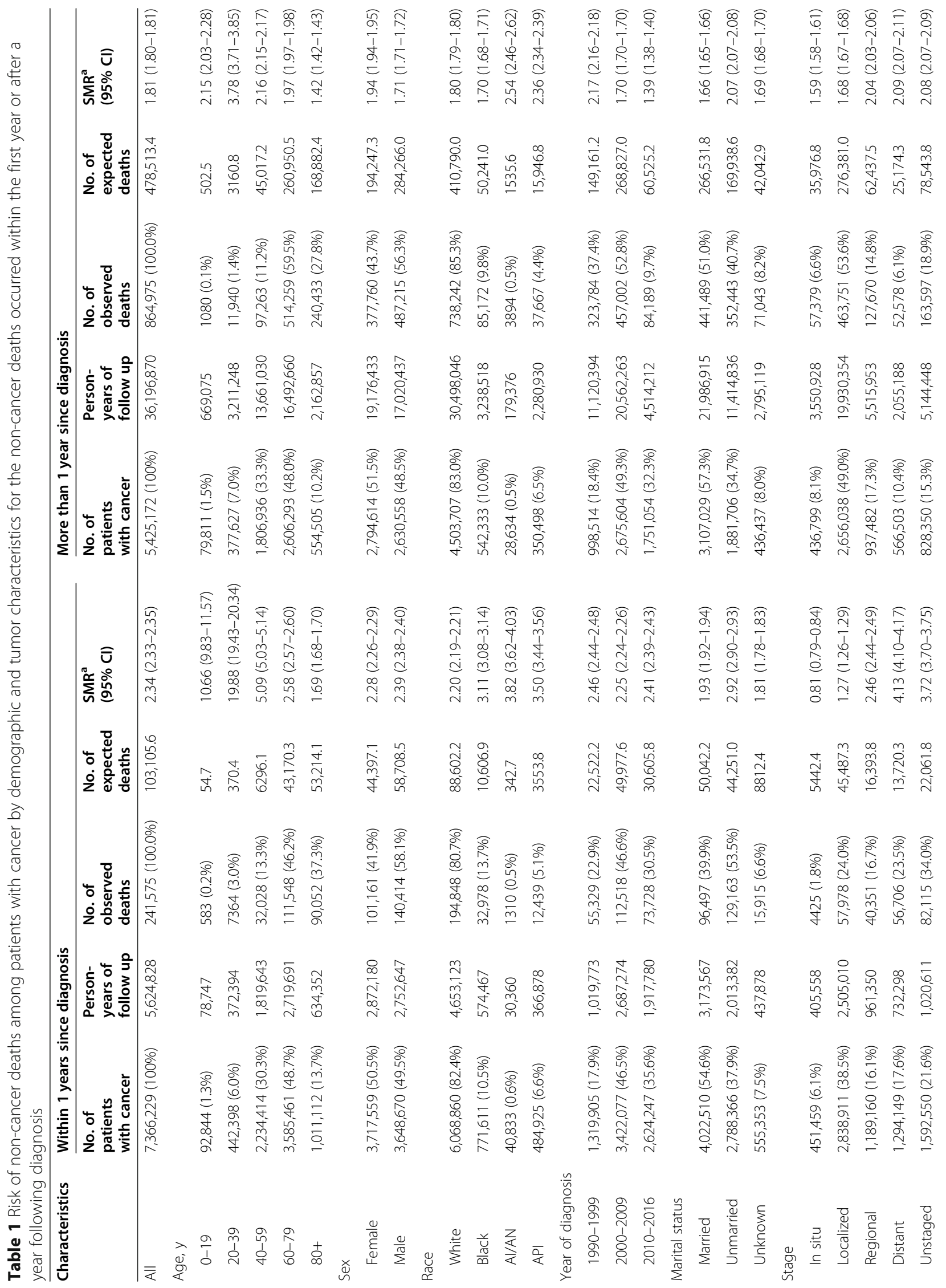




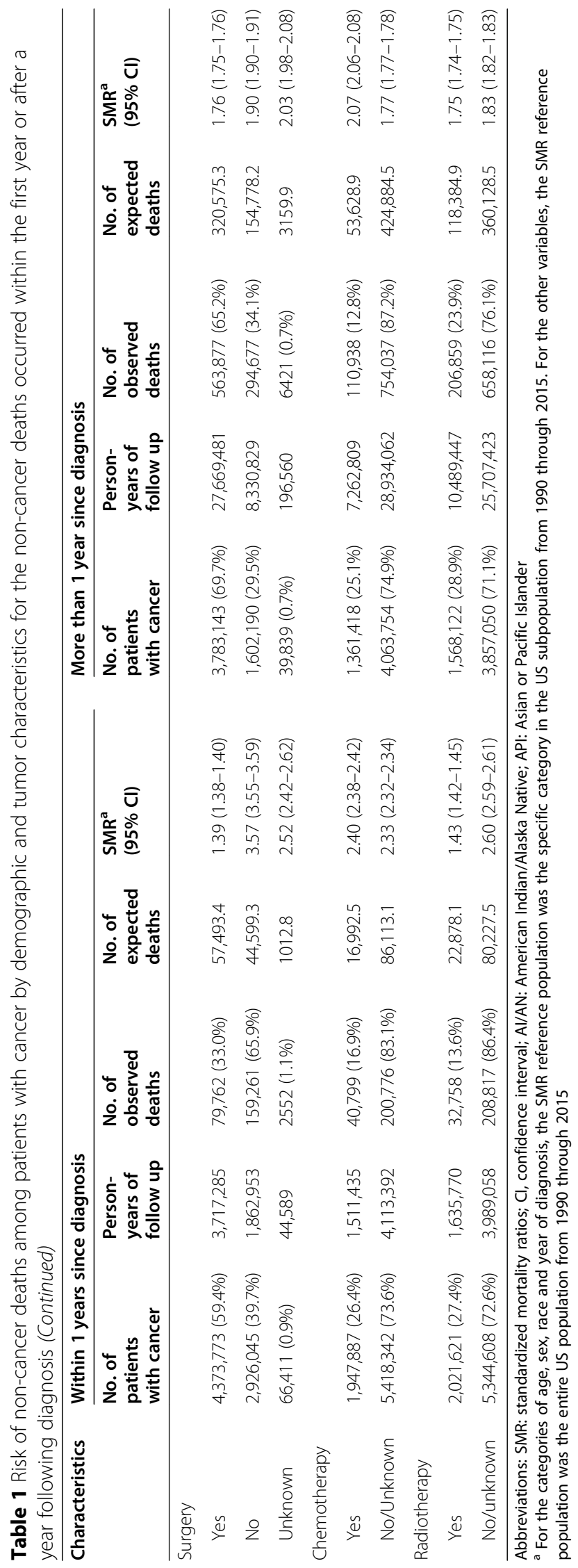


Table 2 Risk of non-cancer deaths for the 25 major types of non-cancer causes within the first year after diagnosis among cancer patients

\begin{tabular}{|c|c|c|c|c|}
\hline Cause & No. of observed deaths & Mortality rate & No. of expected deaths & SMR $(95 \% \mathrm{Cl})$ \\
\hline Cardiovascular diseases & $105,518(21.8 \%)$ & 1875.9 & $52,130.6$ & $2.02(2.01-2.04)$ \\
\hline Diseases of heart & $82,346(17.0 \%)$ & 1464.0 & $39,992.2$ & $2.06(2.05-2.07)$ \\
\hline Cerebrovascular diseases & $15,959(3.3 \%)$ & 283.7 & 8718.0 & $1.83(1.80-1.86)$ \\
\hline Hypertension without heart disease & $3039(0.6 \%)$ & 54.0 & 1303.7 & $2.33(2.25-2.42)$ \\
\hline Aortic aneurysm and dissection & $1522(0.3 \%)$ & 27.1 & 865.2 & $1.76(1.67-1.85)$ \\
\hline Atherosclerosis & $1468(0.3 \%)$ & 26.1 & 675.5 & $2.17(2.06-2.29)$ \\
\hline Other diseases of arteries, arterioles, capillaries & $1184(0.2 \%)$ & 21.0 & 573.9 & $2.06(1.95-2.18)$ \\
\hline Infectious diseases & $34,997(7.2 \%)$ & 622.2 & 6889.5 & $5.08(5.03-5.13)$ \\
\hline Pneumonia and influenza & $9799(2.0 \%)$ & 174.2 & 3849.7 & $2.55(2.50-2.60)$ \\
\hline Syphilis & $3(0.001 \%)$ & 0.1 & 1.1 & $2.65(0.85-8.21)$ \\
\hline Tuberculosis & $157(0.03 \%)$ & 2.8 & 48.9 & $3.21(2.75-3.75)$ \\
\hline Septicemia & $7185(1.5 \%)$ & 127.7 & 1870.2 & $3.84(3.75-3.93)$ \\
\hline Other infectious and parasitic diseases including HIV & $17,853(3.7 \%)$ & 317.4 & 856.8 & $20.84(20.53-21.14)$ \\
\hline Respiratory diseases & $21,229(4.4 \%)$ & 377.4 & 8188.6 & $2.59(2.56-2.63)$ \\
\hline Chronic obstructive pulmonary disease and allied cond & $21,229(4.4 \%)$ & 377.4 & 8188.6 & $2.59(2.56-2.63)$ \\
\hline Gastrointestinal and liver diseases & $7338(1.5 \%)$ & 130.5 & 1588.8 & $4.62(4.51-4.73)$ \\
\hline Stomach and duodenal ulcers & $990(0.2 \%)$ & 17.6 & 238.2 & $4.16(3.91-4.42)$ \\
\hline Chronic liver disease and cirrhosis & $6348(1.3 \%)$ & 112.9 & 1349.8 & $4.70(4.59-4.82)$ \\
\hline Renal diseases & $5678(1.2 \%)$ & 100.9 & 2481.6 & $2.29(2.23-2.35)$ \\
\hline Nephritis, nephrotic syndrome and nephrosis & $5678(1.2 \%)$ & 100.9 & 2481.6 & $2.29(2.23-2.35)$ \\
\hline External injuries & $8875(1.8 \%)$ & 157.8 & 4755.9 & $1.87(1.83-1.91)$ \\
\hline Accidents and adverse effects & $6009(1.2 \%)$ & 106.8 & 3614.9 & $1.66(1.62-1.70)$ \\
\hline Suicide and self-inflicted injury & $2653(0.5 \%)$ & 47.2 & 931.6 & $2.85(2.74-2.96)$ \\
\hline Homicide and legal intervention & $213(0.04 \%)$ & 3.8 & 208.1 & $1.02(0.90-1.17)$ \\
\hline Other non-cancer causes of death & $57,940(12.0 \%)$ & 1030.1 & $27,070.3$ & $2.14(2.12-2.16)$ \\
\hline Alzheimers & $3146(0.7 \%)$ & 55.9 & 3728.7 & $0.84(0.81-0.87)$ \\
\hline Diabetes mellitus & $7263(1.5 \%)$ & 129.1 & 4093.4 & $1.77(1.73-1.82)$ \\
\hline Congenital anomalies & $446(0.1 \%)$ & 7.9 & 144.8 & $3.08(2.81-3.38)$ \\
\hline Certain conditions originating in perinatal period & $50(0.01 \%)$ & 0.9 & 15.5 & $3.22(2.44-4.25)$ \\
\hline Complications of pregnancy, childbirth, puerperium ${ }^{a}$ & $173(0.04 \%)$ & 3.1 & 4.7 & $36.62(31.55-42.50)$ \\
\hline Symptoms, signs and ill-defined conditions & $3921(0.8 \%)$ & 69.7 & 1390.4 & $2.82(2.73-2.91)$ \\
\hline Other cause of death & $42,941(8.9 \%)$ & 763.4 & $17,689.8$ & $2.43(2.40-2.45)$ \\
\hline
\end{tabular}

Abbreviations: SMR, standardized mortality ratio; $\mathrm{Cl}$, confidence interval; $\mathrm{HIV}$, human immunodeficiency virus

${ }^{a}$ For the deaths from complications of pregnancy, childbirth, puerperium, which occurred only in female patients, the SMR reference population was the female general population in the United States from 1990 through 2015. For the other causes, the SMR reference population was the entire US population from 1990 through 2015

Except for cancers of the breast, prostate, and nonbasal skin, mortality risks for most types of cancer within the first year after diagnosis were higher than that of the general population (Table 3). Patients with liver cancer (SMR: 12.29; 95\% CI: 12.06-12.53) were at the highest risk of early non-cancer deaths, followed by brain (SMR: 5.51; 95\% CI: 5.32-5.71), lung (SMR: 4.47; 95\% CI: 4.43-4.52), and esophageal cancer (SMR: 4.18; 95\% CI: 4.04-4.32).

\section{Trends in SMR of non-cancer deaths based on time following diagnosis}

The trends of SMR for non-cancer deaths during followup after diagnosis were determined in this cohort (Fig. 2 and Fig. 3). For all causes and sites combined, the highest risk elevation was observed within the first month of diagnosis, and a rapid decrease in the risks was observed during the first-year follow-up. Similar trends were observed in all major non-cancer causes (Fig. 2). In site- 
Table 3 Risk of non-cancer deaths within the first years after diagnosis among patients with cancer by anatomic site

\begin{tabular}{|c|c|c|c|c|c|}
\hline Site $^{a}$ & $\begin{array}{l}\text { No. of patients with } \\
\text { cancer }\end{array}$ & $\begin{array}{l}\text { Person-years of } \\
\text { follow-up }\end{array}$ & $\begin{array}{l}\text { No. of observed } \\
\text { deaths }\end{array}$ & $\begin{array}{l}\text { No. of expected } \\
\text { deaths }\end{array}$ & SMR (95\% CI) \\
\hline All sites & $7,366,229(100 \%)$ & $5,624,828$ & $241,575(100 \%)$ & $103,105.6$ & $2.34(2.33-2.35)$ \\
\hline Liver & $111,247(1.5 \%)$ & 55,822 & $10,224(4.2 \%)$ & 831.8 & $\begin{array}{l}12.29(12.06- \\
12.53)\end{array}$ \\
\hline Brain & $106,651(1.4 \%)$ & 70,145 & $3047(1.3 \%)$ & 552.6 & $5.51(5.32-5.71)$ \\
\hline Lung and bronchus & $809,032(11.0 \%)$ & 445,176 & $42,791(17.7 \%)$ & 9566.6 & $4.47(4.43-4.52)$ \\
\hline Esophagus & $62,611(0.8 \%)$ & 37,184 & $3291(1.4 \%)$ & 788.1 & $4.18(4.04-4.32)$ \\
\hline Pancreas & $167,632(2.3 \%)$ & 73,063 & $6406(2.7 \%)$ & 1617.9 & $3.96(3.86-4.06)$ \\
\hline Lymphoma & 319,815 (4.3\%) & 244,742 & 16,157 (6.7\%) & 4123.7 & $3.92(3.86-3.98)$ \\
\hline Myeloma & $88,691(1.2 \%)$ & 65,552 & $5460(2.3 \%)$ & 1460.8 & $3.74(3.64-3.84)$ \\
\hline Stomach & $112,398(1.5 \%)$ & 67,433 & $5522(2.3 \%)$ & 1599.0 & $3.45(3.36-3.55)$ \\
\hline Leukemia & $186,654(2.5 \%)$ & 132,021 & $8583(3.6 \%)$ & 2493.8 & $3.44(3.37-3.52)$ \\
\hline Cervix uteri ${ }^{b}$ & $70,499(1.0 \%)$ & 57,734 & $1149(0.5 \%)$ & 344.5 & $3.33(3.15-3.53)$ \\
\hline $\begin{array}{l}\text { Cranial nerves other nervous } \\
\text { system }\end{array}$ & $123,844(1.7 \%)$ & 100,873 & $4947(2.0 \%)$ & 1796.7 & $2.75(2.68-2.83)$ \\
\hline Anus & $31,767(0.4 \%)$ & 26,380 & $882(0.4 \%)$ & 323.5 & $2.73(2.55-2.91)$ \\
\hline Larynx & $54,655(0.7 \%)$ & 44,687 & $2191(0.9 \%)$ & 807.9 & $2.71(2.60-2.83)$ \\
\hline Oral cavity and pharynx & $160,831(2.2 \%)$ & 129,003 & $5441(2.3 \%)$ & 2063.2 & $2.64(2.57-2.71)$ \\
\hline Ovary $^{\mathrm{b}}$ & $109,496(1.5 \%)$ & 81,095 & $2477(1.0 \%)$ & 979.9 & $2.53(2.43-2.63)$ \\
\hline Kidney and renal pelvis & $198,567(2.7 \%)$ & 154,145 & $6206(2.6 \%)$ & 2486.7 & $2.50(2.43-2.56)$ \\
\hline Testis $^{b}$ & $46,488(0.6 \%)$ & 40,099 & $241(0.1 \%)$ & 97.3 & $2.48(2.18-2.81)$ \\
\hline Colon and rectum & $682,370(9.3 \%)$ & 530,418 & $29,597(12.3 \%)$ & $13,105.5$ & $2.26(2.23-2.28)$ \\
\hline Soft tissue including heart & $45,685(0.6 \%)$ & 36,157 & $1033(0.4 \%)$ & 513.2 & $2.01(1.89-2.14)$ \\
\hline Endocrine system & $228,233(3.1 \%)$ & 193,951 & $2110(0.9 \%)$ & 1184.5 & $1.78(1.71-1.86)$ \\
\hline Urinary bladder & $261,604(3.6 \%)$ & 213,851 & $11,290(4.7 \%)$ & 6537.2 & $1.73(1.70-1.76)$ \\
\hline Vulva ${ }^{b}$ & $43,166(0.6 \%)$ & 36,857 & $818(0.3 \%)$ & 481.4 & $1.70(1.59-1.82)$ \\
\hline Corpus uteri ${ }^{b}$ & $208,523(2.8 \%)$ & 173,569 & $3604(1.5 \%)$ & 2167.5 & $1.66(1.61-1.72)$ \\
\hline Breast & $1,221,821(16.6 \%)$ & $1,060,827$ & $12,947(5.4 \%)$ & $13,537.5$ & $0.96(0.94-0.97)$ \\
\hline Skin, non-basal & $457,007(6.2 \%)$ & 389,550 & $5822(2.4 \%)$ & 6761.9 & $0.86(0.84-0.88)$ \\
\hline Prostate $^{\mathrm{b}}$ & $1,044,123(14.2 \%)$ & 911,841 & $17,582(7.3 \%)$ & $21,074.9$ & $0.83(0.82-0.85)$ \\
\hline
\end{tabular}

Abbreviations: SMR, standardized mortality ratio; $\mathrm{Cl}$, confidence interval;

${ }^{a}$ To minimize the Cls of site-specific SMR, data are presented only for persons with those forms of cancer in which 20,000 person-years or more of survival time accrued in the data obtained from the SEER registries. The chosen sites represent for over $85 \%$ of all cancer patients included in the study

${ }^{b}$ For patients with cancers of ovary, vulva, corpus uteri and cervix uteri, which occurred only in female patients, the SMR reference population was the female general population in the United States from 1990 through 2015. For patients with cancers of testis and prostate, which occurred only in male patients, the SMR reference population was the male general population in the United States from 1990 through 2015. For the other sites, the SMR reference population was the entire US population from 1990 through 2015

specific analysis, similar trends were found in most sites, with only a few exceptions (cancers of the anus, nonbasal skin, and testis) (Fig. 3).

\section{Anatomic site-specific analysis for the major types of non-cancer causes of death}

For the major types of non-cancer deaths, the sitespecific analyses are presented in Fig. 4. In terms of mortality from infectious diseases, the SMRs were the highest among those with liver cancer (SMR: 47.03; 95\% CI: 45.29-48.84), lymphomas (SMR: 24.68; 95\% CI: 24.09-25.27), and anal cancer (SMR: 12.27; 95\% CI:
10.89-13.82). The highest SMRs for CVD after a cancer diagnosis were observed for brain cancer (SMR: 5.00; 95\% CI: 4.73-5.28), followed by liver (SMR: 4.24; 95\% CI: 4.04-4.44) and lung cancer (SMR: 3.79; 95\% CI: 3.74-3.85). Among all types of cancer, lung cancer was associated with the highest SMRs for respiratory diseases (SMR: 10.92; 95\% CI: 10.70-11.15), followed by laryngeal cancer (SMR: 4.83; 95\% CI: 4.32-5.39) and esophageal cancer (SMR: 4.63; 95\% CI: 4.13-5.19). The SMRs for gastrointestinal and liver diseases were remarkably high for those with liver cancer (SMR: 162.60; 95\% CI: 156.70-168.72), pancreatic cancer (SMR: 9.33; 95\% CI: 

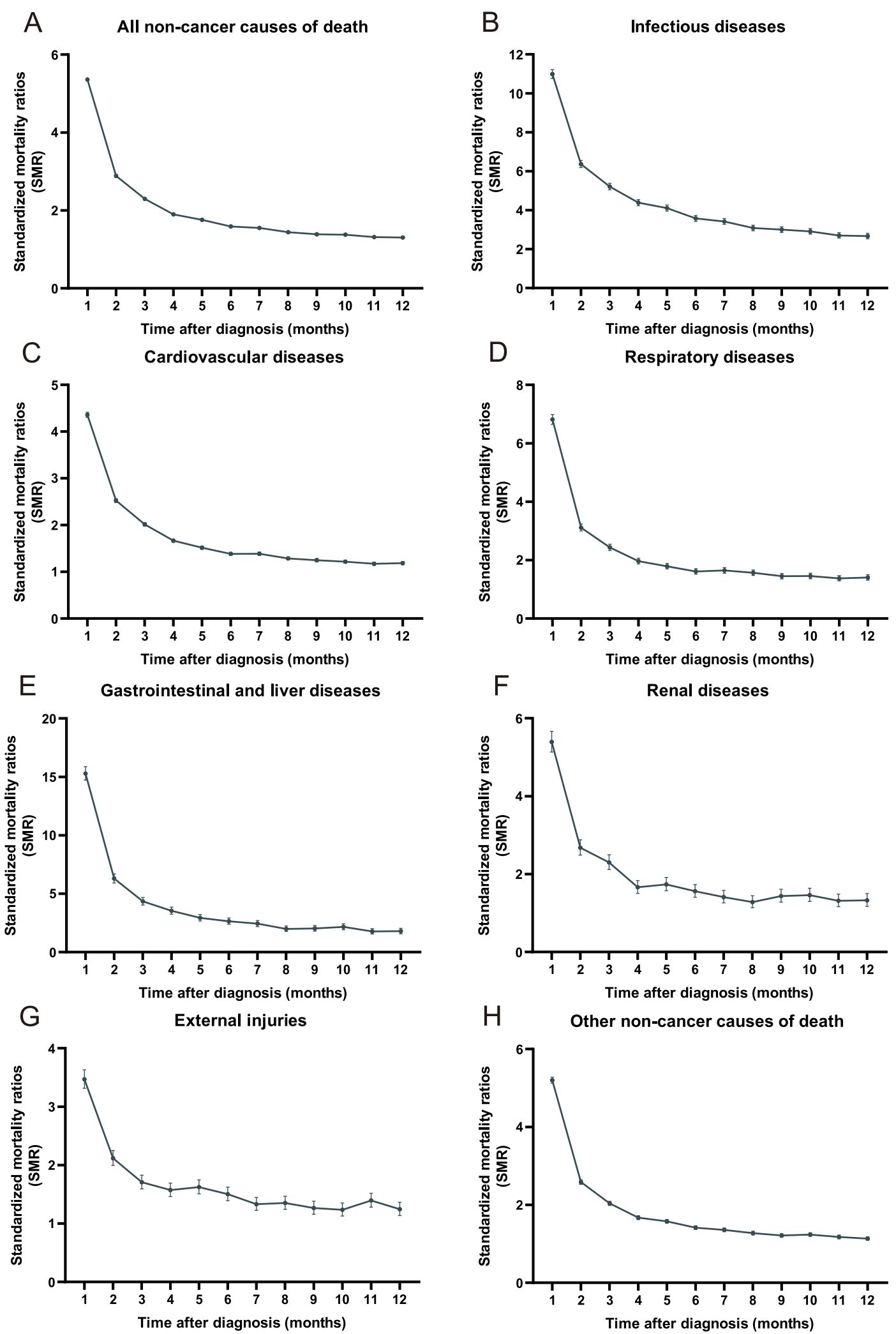

Fig. 2 Risk of deaths from major non-cancer causes by time from diagnosis 


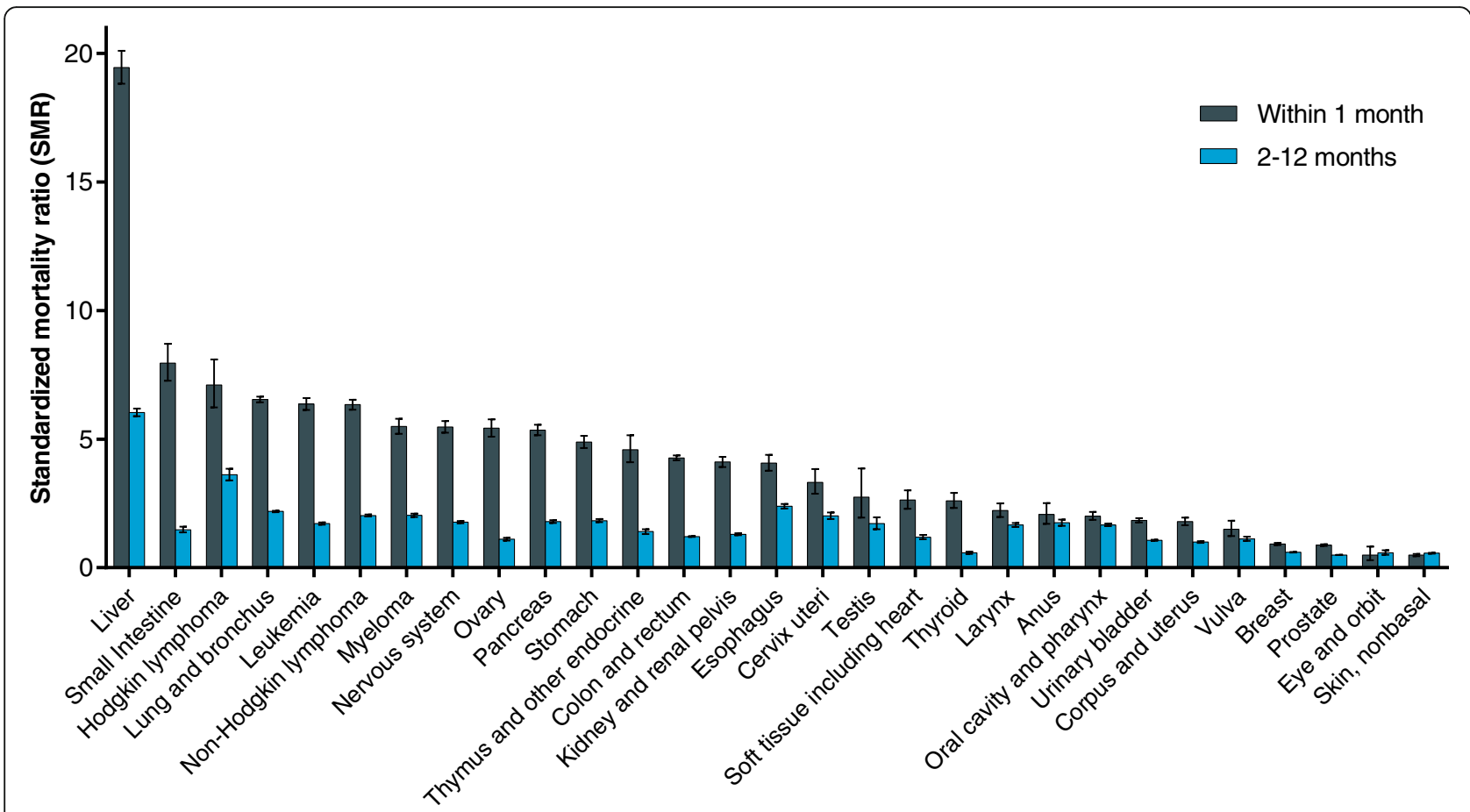

Anatomic site

Fig. 3 Risk of non-cancer deaths within the first year after diagnosis by anatomic site and time from diagnosis

8.16-10.68), and stomach cancer (SMR: 7.21; 95\% CI: 6.15-8.44). For renal diseases, the SMRs were the highest among patients with myelomas (SMR: 9.25 ; 95\% CI: 8.33-10.27), liver cancers (SMR: 7.66; 95\% CI: 6.568.93), cervical cancer (SMR: 4.99; 95\% CI: 3.67-6.77), and renal cancer (SMR: 4.69; 95\% CI: 4.17-5.26). The SMRs for external injuries were remarkably higher among subjects with cancers of the liver (SMR: 4.75; 95\% CI: 4.17-5.40), esophagus (SMR: 4.44; 95\% CI: 3.82-5.16) and lung (SMR: 3.77; 95\% CI: 3.59-3.97).

\section{Discussion}

In our population-based cohort study including more than 7 million patients with cancer, the risk of noncancer deaths was particularly increased within the first year after diagnosis; mortality was approximately 2.34fold that of the general population. The majority of noncancer deaths were caused by CVD, infectious diseases, and respiratory diseases. When compared with the normal population, the risk elevations from infectious diseases were highest in all causes. Patients with liver, brain, and lung cancer are most likely to die of noncancer causes in the first year. The risk of non-cancer deaths was highest in the period immediately following a cancer diagnosis and decreased rapidly.

The majority of non-cancer causes of death within the first year may be largely classified into two groups: chronic comorbidities and acute infections. The most common cause of death from chronic comorbidities is CVD, which mainly includes heart and cerebrovascular diseases (Table 2). We also found that patients with cancer often had accompanying chronic comorbid conditions in the same or adjacent sites. We noted an increase in the risk of death from respiratory diseases (mainly chronic obstructive pulmonary disease [COPD]) in patients with lung cancers. In addition, the risk of deaths from gastrointestinal and liver diseases was highest in the diseases of the digestive organs, including the liver, pancreas, stomach and esophagus (Fig. 4). This may be attributed to the shared causal factors between the comorbid conditions and cancers, particularly in the same or adjacent sites. Lung cancer and COPD, for example, are all caused or aggravated by smoking [15]. In addition, chronic inflammation has been postulated as the obvious culprit linking COPD and lung cancer [16].

As the second predominant cause of death among patients with cancer after a cancer diagnosis, fatal infections have been interpreted to be a consequence of the immunosuppression induced by the effects of the malignancy itself and by various modern cancer therapies, including chemotherapeutic regimens, hematopoietic stem cell transplantation, invasive procedures, or medical devices and malnutrition [17-20]. Consistent with our previous findings, cancer patients had greater risks of dying from infections, and the degree of the risks was 
A All non-cancer causes
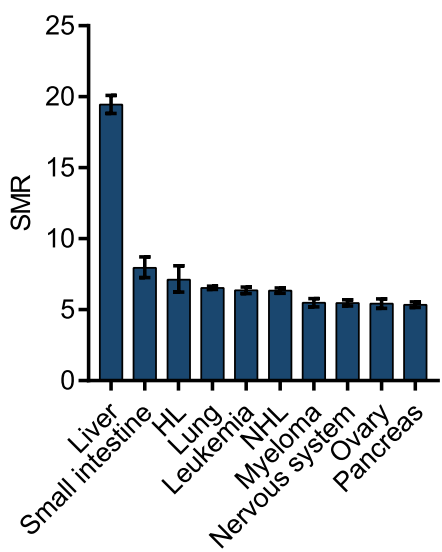

Top 10 anatomic sites

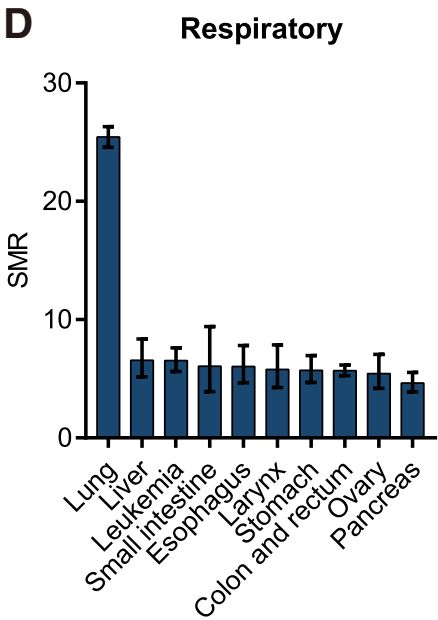

Top 10 anatomic sites

G
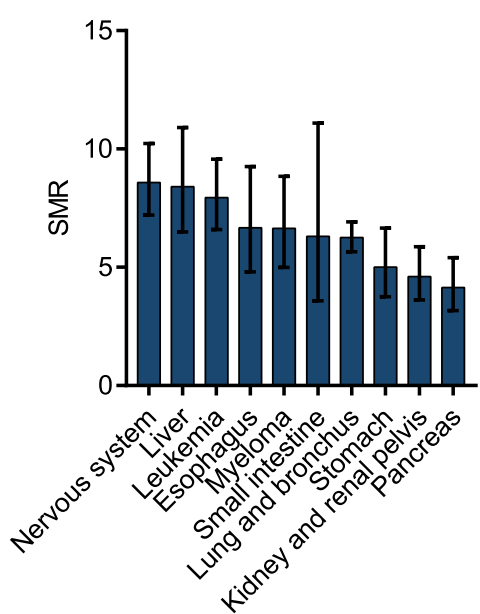

Top 10 anatomic sites

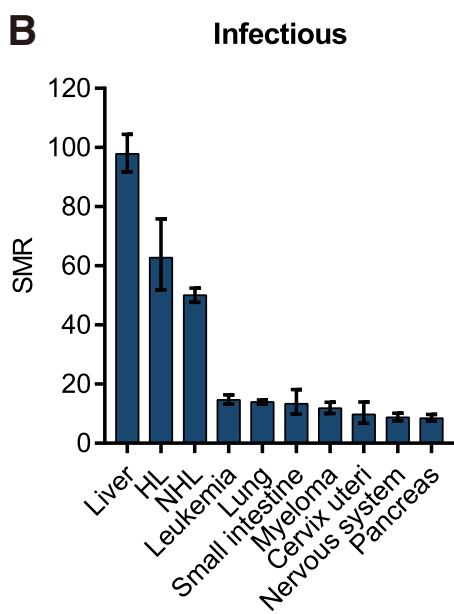

Top 10 anatomic sites

E Gastrointestinal and liver

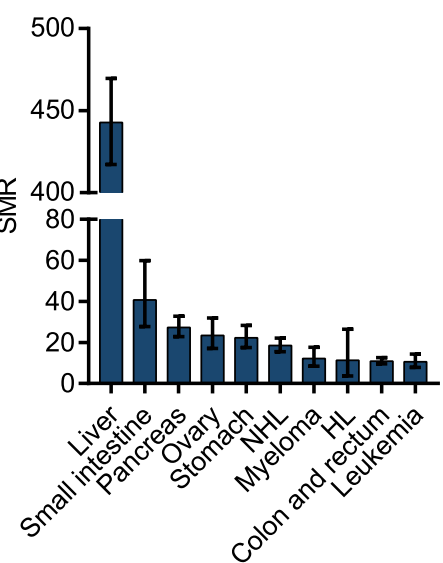

Top 10 anatomic sites

H Other cause of death
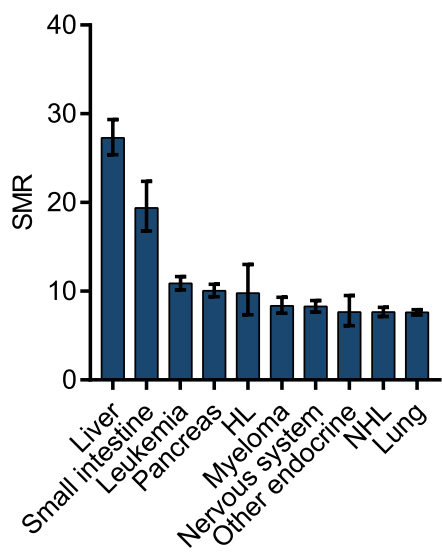

Top 10 anatomic sites

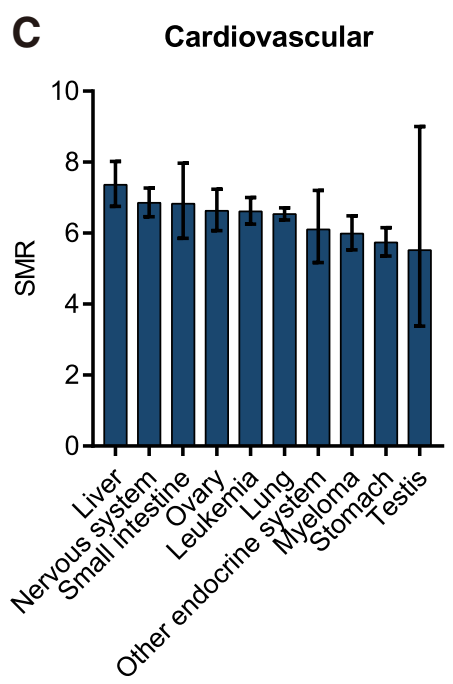

Top 10 anatomic sites

F

Renal
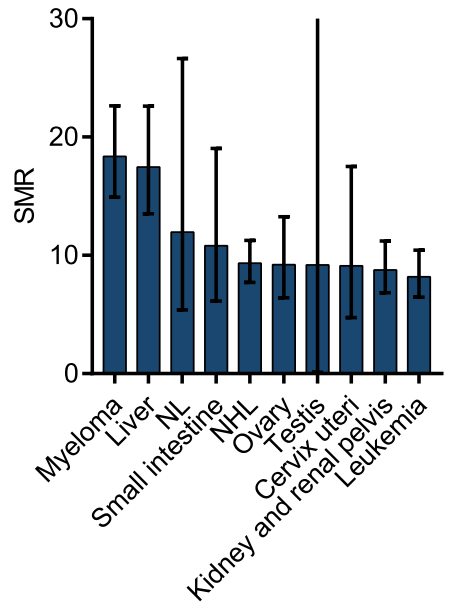

Top 10 anatomic sites

Abbreviations:

HL: Hodgkin lymphoma

NHL: Non-Hodgkin lymphoma

SMR:Standardized mortality ratio.

Fig. 4 Risk of deaths from major non-cancer causes within the first year after diagnosis by anatomic site 
positively correlated with the stages of cancer [21, 22]. In our analyses, the particularly high risk of death from infectious diseases in patients with liver cancer may be attributable to its association with acute or chronic viral hepatitis; this elucidated the important role of viral hepatitis in both the development of and mortality from liver cancer [23, 24]. As shown in Fig. 4, elevated SMRs for infectious diseases were also observed in nearly all hematological malignancies, including lymphomas, leukemias, and myelomas; this reflected the substantial risks of immune-compromise induced by hematologic malignancies and iatrogenic immunosuppression caused by systemic chemotherapy and hematopoietic stem cell transplantation [25, 26]. Furthermore, the notably high SMRs in patients with lymphomas probably reflects its relation with human immunodeficiency virus (HIV) infection, particularly since our study covered the period of increase in the burden of HIV infection [27, 28]. The findings of our study indicate the underlying interactive correlation between infection and cancer. Immunosuppression induced by cancer and its treatments may play an important role in infectious disease complications. Conversely, previous studies also revealed the important role that infectious agents play in carcinogenesis $[17,18$, 29, 30]. Therefore, strategies to control infectious diseases, both before and after a cancer diagnosis, should be optimized. Following accumulation of all non-cancer causes, the risk of non-cancer deaths was highest in patients with liver cancers. As the third leading cause of cancer-related mortality worldwide, the poor prognosis of liver cancer may have contributed considerably to these results [31]. Additionally, liver cancer and the noncancer co-morbidities share certain potential risk factors (modifiable and non-modifiable). As described previously, in addition to the strong association between acute or chronic viral hepatitis with the development of liver cancer, they were also related with the particularly high risks of infectious disease complications in these patients [23, 24]. Consequently, the mortalities of both chronic liver disease and infectious disease complications were substantially elevated in patents with liver cancer. The high mortality from heart disease in patients with liver cancer may be attributed to the shared causal factors among these conditions, including increasing age, male sex, diet, alcohol abuse, tobacco smoking, and fatty and nonalcoholic fatty liver disease [32-35].

Among the different types of cancer, lung cancer was responsible for the highest number of non-cancer deaths, and also had a significantly elevated SMR. Lung cancer is the most common malignancy and the leading cause of death worldwide [31]. In this study, we found that lung cancer was also a leading cause of death involving non-cancer comorbidities in the first year following diagnosis. Besides, the risk factors of lung cancer, such as age and smoking, are also strongly associated with non-cancer comorbidities, including diseases of the cardiovascular, pulmonary and other systems [36].

Interestingly, the risk of death from renal diseases was markedly high in patients with myeloma. Renal insufficiency in myeloma patients is mainly caused by renal impairment resulting from the accumulation and precipitation of homogeneous immunoglobulins or light chains; the predominant renal pathology is cast nephropathy [37]. Renal involvement may manifest as acute or chronic renal failure, nephrotic syndrome, non-nephrotic proteinuria, or tubular function defects [37, 38].

The main strength of our study was that it included a population-based cohort and comprehensively obtained the diagnostic confirmation of cancers and their fatal outcomes. However, there were several limitations. First, the causes of death may have been potentially misclassified due to inaccurate coding in the death certificates [39]. However, previous studies have shown that for several non-cancer causes of death, including coronary heart disease [40] and suicide [41, 42], the cause of death codes obtained from death certificates are reasonably valid (sensitivity and specificity $>70 \%$ ) compared to the gold standard assessment of the cause of death [40, 43]. In addition, systematic and standardized data collection procedures are used to ensure that the causes of death recoded in the SEER are accurate [44].

Second, in view of maintaining confidentiality, deaths from HIV and other infections, including viral hepatitis and parasitic diseases are incorporated under a single code in the SEER database [7]. Therefore, the direct contribution of deaths from HIV, viral hepatitis, and other infections, to the increase of SMR in patients with cancer could not be accurately assessed.

Third, the SEER database does not provide detailed information on cancer treatment; this precluded the analysis of non-cancer mortality based on receipt of specific chemotherapy drugs and/or doses of chemotherapy or radiotherapy.

Finally, personal information on family history or genetics was not available in the SEER database, thus our analysis could not provide insight on the role of heredity in risk of non-cancer deaths.

\section{Conclusions}

Risks from non-cancer deaths significantly increase in the first year following a cancer diagnosis in comparison with the general population, particularly in the first month. Risks of non-cancer deaths vary by the types of causes and anatomic sites of cancer. Our data underscore the importance of comprehensive and early multidisciplinary care for mitigating such risks. 


\section{Abbreviations}

SEER: Surveillance, Epidemiology, and End Results; SMR: Standardized Mortality Ratios; Cl: Cofidence Interval; CVD: Cardiovascular Disease

\section{Acknowledgments}

The interpretation and reporting of these data are the sole responsibility of the authors. The authors acknowledge the efforts of the National Cancer Institute and the Surveillance, Epidemiology, and End Results (SEER) Program tumor registries in the creation of the SEER database.

\section{Authors' contributions}

Dr. B. Wu had full access to all of the data in the study and takes responsibility for the integrity of the data and the accuracy of the data analysis. Concept and design: B. Wu, Y. Zheng, P. Yang. Acquisition, analysis, or interpretation of data: All authors. Drafting of the manuscript: J. Chen, Y. Chen. Critical revision of the manuscript for important intellectual content: B. Wu, Y. Yang, H. Ma. Statistical analysis: P. Yang, Y. Zheng, K. Yu. Administrative, technical, or material support: Y. Zheng, P. Yang, J. Chen. Supervision: B. Wu. All of the author(s) read and approved the final manuscript.

\section{Funding}

This work has no funding.

\section{Availability of data and materials}

The datasets generated and analyzed during the current study are available in the SEER repository (https://seer.cancer.gov/seerstat/).

\section{Declarations}

\section{Ethics approval and consent to participate}

Not applicable.

\section{Consent for publication}

Not applicable.

\section{Competing interests}

The authors declare that they have no competing interests.

\section{Author details}

'Division of Gastroenterology, Union Hospital, Tongii Medical College, Huazhong University of Science and Technology, Wuhan 430022, China. ${ }^{2}$ Cancer Center, Union Hospital, Tongji Medical College, Huazhong University of Science and Technology, Wuhan 430022, China. ${ }^{3}$ State Key Laboratory of Oncology in South China, Sun Yat-sen University Cancer Center, Sun Yat-sen University, Guangzhou 510060, China.

\section{Received: 5 February 2021 Accepted: 18 August 2021}

\section{Published online: 27 August 2021}

\section{References}

1. Zaorsky NG, Churilla TM, Egleston BL, Fisher SG, Ridge JA, Horwitz EM, et al. Causes of death among cancer patients. Ann Oncol. 2017;28(2):400-7. https://doi.org/10.1093/annonc/mdw604.

2. Shen Q, Lu D, Schelin ME, et al. Injuries before and after diagnosis of cancer: nationwide register based study. Bmj. 2016;354:14218.

3. Fang F, Fall K, Mittleman MA, Sparén P, Ye W, Adami HO, et al. Suicide and cardiovascular death after a cancer diagnosis. N Engl J Med. 2012;366(14): 1310-8. https://doi.org/10.1056/NEJMoa1110307.

4. Saad AM, Gad MM, Al-Husseini MJ, et al. Suicidal death within a year of a cancer diagnosis: a population-based study. Cancer. 2019;125(6):972-9. https://doi.org/10.1002/cncr.31876.

5. Surveillance Research Program, National Cancer Institute. SEER*Stat software (www.seer.cancer.gov/seerstat) version 8.3.6.

6. Surveillance Epidemiology and End Results: Mortality-all COD, public-use with state, Total US (1990-2016), surveillance, Epidemiology, and end Results (SEER) program SEER*stat Databas. Accessed 15 July 2019.

7. Surveillance, Epidemiology, and End Results Program. SEER Cause of Death Recode 1969+ (04/16/2012). https://seer.cancer.gov/codrecode/1969+_d041 62012/index.html. Published March 2018. Accessed 15 July 2019.
8. Anderson C, Lund JL, Weaver MA, Wood WA, Olshan AF, Nichols HB. Noncancer mortality among adolescents and young adults with cancer. Cancer. 2019;125(12):2107-14. https://doi.org/10.1002/cncr.32063.

9. Koepsell TD, Weiss NS. Epidemiologic methods: studying the occurrence of illness. New York: Oxford University Press; 2003.

10. Misono S, Weiss NS, Fann JR, Redman M, Yueh B. Incidence of suicide in persons with cancer. J Clin Oncol. 2008;26(29):4731-8. https://doi.org/10.12 00/JCO.2007.13.8941.

11. Breslow NE, Day NE. Statistical methods in cancer research. Volume II--The design and analysis of cohort studies. IARC Sci Public. 1987;82:1-406.

12. Yang K, Zheng Y, Peng J, Chen J, Feng H, Yu K, et al. Incidence of death from unintentional injury among patients with Cancer in the United States. JAMA Netw Open. 2020;3(2):e1921647. https://doi.org/10.1001/jama networkopen.2019.21647.

13. Ury HK, Wiggins AD. Another shortcut method for calculating the confidence interval of a Poisson variable (or of a standardized mortality ratio). Am J Epidemiol. 1985;122(1):197-8. https://doi.org/10.1093/ oxfordjournals.aje.a114083.

14. R Core Team. R: A language and environment for statistical computing. R Foundation for Statistical Computing, Vienna, Austria. 2018. Accessed at www.R-project.org/.

15. Seijo LM, Zulueta JJ. Understanding the links between lung Cancer, COPD, and emphysema: a key to more effective treatment and screening. Oncology (Williston Park). 2017;31(2):93-102.

16. Houghton AM, Mouded M, Shapiro SD. Common origins of lung cancer and COPD. Nat Med. 2008;14(10):1023-4. https://doi.org/10.1038/nm1008-1023.

17. Chanock S. Evolving risk factors for infectious complications of cancer therapy. Hematol Oncol Clin North Am. 1993;7(4):771-93. https://doi.org/1 0.1016/50889-8588(18)30221-1.

18. Zembower TR. Epidemiology of infections in cancer patients. Cancer Treat Res. 2014;161:43-89. https://doi.org/10.1007/978-3-319-04220-6_2.

19. Donnelly JP, Blijlevens NM, van der Velden WJ. Host impairments in patients with neoplastic diseases. Cancer Treat Res. 2014;161:1-41. https://doi.org/1 0.1007/978-3-319-04220-6_1.

20. Gedik H, Simsek F, Kanturk A, et al. Bloodstream infections in patients with hematological malignancies: which is more fatal - cancer or resistant pathogens? Ther Clin Risk Manag. 2014;10:743-52. https://doi.org/10.2147/TCRM.S68450.

21. Zheng Y, Chen Y, Yu K, Yang Y, Wang X, Yang X, et al. Fatal infections among Cancer patients: a population-based study in the United States. Infect Dis Ther. 2021:10(2):871-95. https://doi.org/10.1007/s40121-021-00433-7.

22. Saleh R, Elkord E. Acquired resistance to cancer immunotherapy: role of tumor-mediated immunosuppression. Semin Cancer Biol. 2020;65:13-27. https://doi.org/10.1016/j.semcancer.2019.07.017.

23. Perz JF, Armstrong GL, Farrington LA, Hutin YJ, Bell BP. The contributions of hepatitis $B$ virus and hepatitis $C$ virus infections to cirrhosis and primary liver cancer worldwide. J Hepatol. 2006;45(4):529-38. https://doi.org/10.1016/j. jhep.2006.05.013.

24. Ringelhan M, McKeating JA, Protzer U. Viral hepatitis and liver cancer. Philos Trans R Soc Lond B Biol Sci. 2017;372(1732):20160274. https://doi.org/10.1 098/rstb.2016.0274.

25. Gudiol C, Aguado JM, Carratala J. Bloodstream infections in patients with solid tumors. Virulence. 2016;7(3):298-308. https://doi.org/10.1080/21 505594.2016.1141161.

26. Fuji S, Kapp M, Einsele H. Challenges to preventing infectious complications, decreasing re-hospitalizations, and reducing cost burden in long-term survivors after allogeneic hematopoietic stem cell transplantation. Semin Hematol. 2012;49(1):10-4. https:/doi.org/10.1053/j.seminhematol.2011.10.009.

27. Shiels MS, Engels EA, Linet MS, Clarke CA, Li J, Hall HI, et al. The epidemic of non-Hodgkin lymphoma in the United States: disentangling the effect of HIV, 1992-2009. Cancer Epidemiol Biomark Prev. 2013;22(6):1069-78. https:// doi.org/10.1158/1055-9965.EPI-13-0040.

28. Hall HI, Song R, Tang T, An Q, Prejean J, Dietz P, et al. HIV trends in the United States: diagnoses and estimated incidence. JMIR Public Health Surveill. 2017;3(1):e8. https://doi.org/10.2196/publichealth.7051.

29. Baden LR, Swaminathan S, Angarone M, Blouin G, Camins BC, Casper C, et al. Prevention and treatment of Cancer-related infections, version 2.2016, NCCN clinical practice guidelines in oncology. J Natl Compr Cancer Netw. 2016;14(7):882-913. https://doi.org/10.6004/jnccn.2016.0093.

30. Masrour-Roudsari J, Ebrahimpour S. Causal role of infectious agents in cancer: an overview. Caspian J Intern Med. 2017;8(3):153-8. https://doi.org/1 0.22088/cjim.8.3.153 
31. Bray F, Ferlay J, Soerjomataram I, Siegel RL, Torre LA, Jemal A. Global cancer statistics 2018: GLOBOCAN estimates of incidence and mortality worldwide for 36 cancers in 185 countries. CA Cancer J Clin. 2018;68(6):394-424. https://doi.org/10.3322/caac.21492.

32. Grandhi MS, Kim AK, Ronnekleiv-Kelly SM, Kamel IR, Ghasebeh MA, Pawlik TM. Hepatocellular carcinoma: From diagnosis to treatment. Surg Oncol. 2016;25(2):74-85. https://doi.org/10.1016/j.suronc.2016.03.002.

33. Forner A, Reig M, Bruix J. Hepatocellular carcinoma. Lancet. 2018;391(10127): 1301-14. https://doi.org/10.1016/S0140-6736(18)30010-2.

34. Khot UN, Khot MB, Bajzer CT, Sapp SK, Ohman EM, Brener SJ, et al. Prevalence of conventional risk factors in patients with coronary heart disease. JAMA. 2003;290(7):898-904. https://doi.org/10.1001/jama.290.7.898.

35. Lonardo A, Sookoian S, Pirola CJ, Targher G. Non-alcoholic fatty liver disease and risk of cardiovascular disease. Metabolism. 2016;65(8):1136-50. https:// doi.org/10.1016/.metabol.2015.09.017.

36. Dutkowska AE, Antczak A. Comorbidities in lung cancer. Pneumonol Alergol Pol. 2016;84(3):186-92. https://doi.org/10.5603/PiAP.2016.0022

37. Sakhuja V, Jha V, Varma S, Joshi K, Gupta KL, Sud K, et al. Renal involvement in multiple myeloma: a 10-year study. Ren Fail. 2000;22(4):465-77. https:// doi.org/10.1081/JDI-100100888.

38. Stompor T, Zablocki M, Pankrac K. Renal involvement in multiple myeloma. Pol Arch Med Wewn. 2012;122(9):443-8.

39. Park HS, Lloyd S, Decker RH, Wilson LD, Yu JB. Limitations and biases of the surveillance, Epidemiology, and end Results database. Curr Probl Cancer. 2012;36(4):216-24. https://doi.org/10.1016/j.currproblcancer.2012.03.011.

40. Lloyd-Jones DM, Martin DO, Larson MG, Levy D. Accuracy of death certificates for coding coronary heart disease as the cause of death. Ann Intern Med. 1998; 129(12):1020-6. https://doi.org/10.7326/0003-4819-129-12-199812150-00005.

41. Moyer LA, Boyle CA, Pollock DA. Validity of death certificates for injury related causes of death. Am J Epidemiol. 1989;130(5):1024-32. https://doi. org/10.1093/oxfordjournals.aje.a115403.

42. Huusko R, Hirvonen J. The problem of determining the manner of death as suicide or accident in borderline cases. Zeitschrift fur Rechtsmedizin Journal of legal medicine. 1988;100(2-3):207-13. https:/doi.org/10.1007/BF00200761.

43. Coady SA, Sorlie PD, Cooper LS, Folsom AR, Rosamond WD, Conwill DE. Validation of death certificate diagnosis for coronary heart disease: the atherosclerosis risk in communities (ARIC) study. J Clin Epidemiol. 2001;54(1): 40-50. https://doi.org/10.1016/S0895-4356(00)00272-9.

44. Park HS, Lloyd S, Decker RH, Wilson LD, Yu JB. Overview of the surveillance, Epidemiology, and end Results database: evolution, data variables, and quality assurance. Curr Probl Cancer. 2012;36(4):183-90. https://doi.org/10.1 016/j.currproblcancer.2012.03.007.

\section{Publisher's Note}

Springer Nature remains neutral with regard to jurisdictional claims in published maps and institutional affiliations.

Ready to submit your research? Choose BMC and benefit from:

- fast, convenient online submission

- thorough peer review by experienced researchers in your field

- rapid publication on acceptance

- support for research data, including large and complex data types

- gold Open Access which fosters wider collaboration and increased citations

- maximum visibility for your research: over $100 \mathrm{M}$ website views per year

At $\mathrm{BMC}$, research is always in progress.

Learn more biomedcentral.com/submissions 